\title{
Non-B, non-C hepatocellular carcinoma (Review)
}

\author{
HIROKI NISHIKAWA and YUKIO OSAKI
}

Department of Gastroenterology and Hepatology, Osaka Red Cross Hospital, Tennoji-ku, Osaka 543-0027, Japan

Received June 10, 2013; Accepted July 16, 2013

DOI: $10.3892 /$ ijo.2013.2061

\begin{abstract}
Although most hepatocellular carcinoma (HCC) is related to viral infection, there is a substantial population of HCC patients (5-20\%) who are negative for both markers of hepatitis $\mathrm{B}$ virus and hepatitis $\mathrm{C}$ virus infection [non- $\mathrm{B}$, non- $\mathrm{C}$ (NBNC) hepatitis] in Japan and the incidence of NBNC-HCC has recently tended to increase. The most common cause of liver disease in developed countries is non-alcoholic fatty liver disease (NAFLD), which includes non-alcoholic steatohepatitis (NASH) and its related complications. Increased body mass index and diabetes mellitus are associated with developing NAFLD and NASH, which is a severe form of NAFLD. Furthermore, increasing clinical evidence supports the fact that NAFLD and NASH can progress to liver cirrhosis and even HCC. A detailed understanding of the epidemiology, etiology, molecular mechanism, clinical features and prognosis of NBNC-HCC could improve our screening and therapy of this disease. In this review, we primarily focus on clinical aspects of NBNC-HCC and refer to our current knowledge of this cancer.
\end{abstract}

\section{Contents}

1. Introduction

2. Epidemiological trends, etiology and risk factors of NBNC-HCC

3. Alcohol-related HCC

4. NAFLD and NASH

5. DM

6. Obesity

7. Iron

8. Other causes

9. Mechanism of carcinogenesis in NBNC-HCC

10. Clinicopathological features and prognosis in patients with NBNC-HCC

11. Conclusion

Correspondence to: Dr Hiroki Nishikawa, Department of Gastroenterology and Hepatology, Osaka Red Cross Hospital, 5-30 Fudegasaki-cho, Tennoji-ku, Osaka 543-0027, Japan

E-mail: h-nishikawa@osaka-med.jrc.or.jp

Key words: non-B, non-C hepatocellular carcinoma, epidemiology, non-alcoholic fatty liver disease, non-alcoholic steatohepatitis, carcinogenesis, prognosis

\section{Introduction}

Hepatocellular carcinoma (HCC) is a common malignancy in Asia and South Africa. HCC usually develops in patients with hepatitis $\mathrm{B}$ virus (HBV) infection, hepatitis $\mathrm{C}$ virus (HCV) infection and alcoholic liver disease (1-3). HCC is diagnosed in more than half a million people worldwide each year, and therefore it is a major global health problem. HCC is the fifth most common cancer in the world and the third most common cause of cancer-related death, behind only lung cancer and gastric cancer (1-5). Japan has one of the highest rates of incidence of HCC among developed countries (4-6).

Although most HCC is related to viral infection, there is a substantial population of HCC patients (5-20\%) who are negative for both markers of $\mathrm{HBV}$ and $\mathrm{HCV}$ infection [non-B, non-C (NBNC) hepatitis] in Japan and the incidence of NBNC-HCC has recently tended to increase (7-12). Furthermore, investigations in the US assessing risk factors for chronic liver disease and $\mathrm{HCC}$ have failed to identify $\mathrm{HBV}, \mathrm{HCV}$ or excessive alcohol intake in a large population $(13,14)$.

The most common cause of liver disease in developed countries is non-alcoholic fatty liver disease (NAFLD), which includes non-alcoholic steatohepatitis (NASH) and its related complications $(7,15)$. The incidence of NASH is reported to be $1-3 \%$ among the adult Japanese population, and $\sim 6 \%$ in Western countries $(7,15)$. Increased body mass index (BMI) and diabetes mellitus (DM) are associated with developing NAFLD and NASH, which is a severe form of NAFLD (17). Increasing clinical evidence supports the fact that NAFLD and NASH can progress to liver cirrhosis and HCC (7,13-16). The exponentially growing incidence of HCC may be partially attributable to increased numbers of patients with NASH-related cirrhosis, although recent evidence demonstrates that NAFLD or NASH may directly promote liver carcinogenesis independent of the presence of liver cirrhosis (15).

Obesity and the metabolic syndrome are growing epidemics related to an increased risk for several types of cancer including HCC (16). In the liver, inflammatory and angiogenic changes caused by insulin resistance and fatty liver disease are associated with an increased incidence of HCC $(17,18)$. In contrast, regardless of underlying liver disease, liver cirrhosis remains the most important risk factor for the development of HCC, although as mentioned earlier, HCC arising without liver cirrhosis raises the possibility of direct carcinogenesis.

A detailed understanding of the epidemiology, etiology, molecular mechanism, clinical features and prognosis associated with NBNC-HCC could improve our screening and 


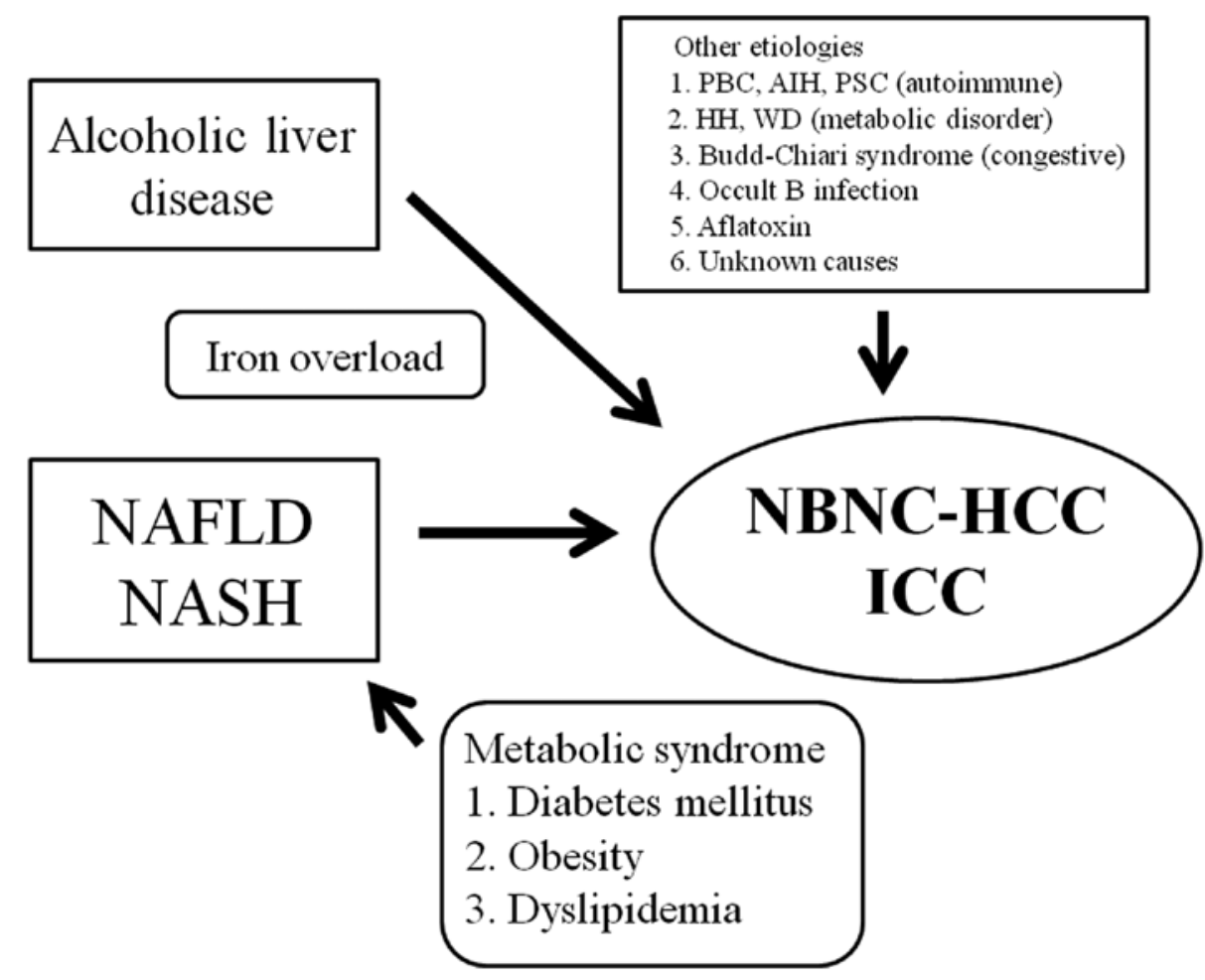

Figure 1. Schematic representation of the etiology of NBNC-HCC. NAFLD, non-alcoholic fatty liver disease; NASH, non-alcoholic steatohepatitis; ICC, intrahepatic cholangiocarcinoma; PBC, primary biliary cirrhosis; AIH, autoimmune hepatitis; PSC, primary sclerosing cholangitis; HH, hereditary hemochromatosis; WD, Wilson disease; OBI, occult hepatitis B infection.

therapy of this disease. In this review, we primarily focus on clinical aspects of NBNC-HCC and refer to our current knowledge of this cancer.

\section{Epidemiological trends, etiology, and risk factors of NBNC-HCC}

The major causes of cirrhosis in HCC are HBV, HCV and alcohol. The risk of HCC increases sharply in response to chronic liver damage at the fibrosis stage (2). HCV infection is the most prevalent risk factor for HCC in Japan $(2,4,5,19)$. In the US, the leading cause of underlying liver disease among $\mathrm{HCC}$ patients is $\mathrm{HCV}(51 \%)$, and the second most common is cryptogenic cirrhosis (CC) (29\%) (14).

Although most HCC still occurs in patients with chronic hepatitis C in Japan, the incidence of HCV-related HCC has been decreasing in recent years because of the improvement of therapy for chronic hepatitis $\mathrm{C}$ and a decrease in the number of patients newly diagnosed with chronic hepatitis $C(6,20-22)$. In addition, there has been a recent increasing trend in NBNC-HCC in Japan (7). Nagaoki et al reported in 1,374 consecutive HCC patients in their institution that 17 and $67 \%$ of $\mathrm{HCC}$ was related to $\mathrm{HBV}$ and $\mathrm{HCV}$, respectively, and $15 \%$ was related to NBNC-HCC (10). Tokushige et al conducted a nationwide survey of 14,530 Japanese HCC patients. They reported that alcohol-related HCC accounted for $7.2 \%$ of all HCC, followed by unknown causes (5.1\%) and NAFLD-related HCC (2.0\%). The characteristics of these three groups were clearly different (median age, 72 years for NAFLD-related HCC, 68 years for alcohol-related HCC, and 73 years for unknown HCC; female sex, 38, 4 and 37\%, respectively) and obesity and lifestyle-related diseases were significantly more frequent in NAFLD- than alcohol-related HCC and unknown HCC (7). Ertle et al reported in 162 HCC patients that HCV-related HCC accounted for $23.3 \%$, HBV-related HCC for $19.9 \%$, alcohol-related HCC for $12.7 \%$, and NAFLD-related HCC for $24.0 \%$ (23).

The background liver diseases of NBNC-HCC vary considerably and they include NAFLD, NASH, alcoholic liver disease, autoimmune liver disease such as autoimmune hepatitis (AIH), primary biliary cirrhosis (PBC), primary sclerosing cholangitis (PSC), congestive liver disease such as Budd-Chiari syndrome (BCS), congenital metabolic liver disease such as hereditary hemochromatosis and Wilson disease, occult HBV infection (OBI) and aflatoxins, as well as liver disease of unknown etiology. Different etiologies of HCC may cause different clinical characteristics and clinical outcomes. Fig. 1 shows a schematic representation of the different etiologies of NBNC-HCC.

\section{Alcohol-related HCC}

The alcohol consumption criterion for defining alcoholic liver disease as proposed by the Japanese Study Group on Alcoholic Liver Disease is an ethanol intake of $>70 \mathrm{~g} /$ day for $>5$ years. As compared with Western countries, the prevalence of alcohol-related HCC is lower in Japan (19). This is partly because of the high incidence of hepatitis virus-related HCC (19).

The mechanism by which alcohol consumption increases the risk of $\mathrm{HCC}$ is primarily due to the development of liver cirrhosis. It has been shown that excessive alcohol consump- 
tion of $>80 \mathrm{~g} /$ day ethanol for $>5$ years increases the risk of HCC by nearly 5-fold (24). According to a meta-analysis from Italy, hazard ratios (HRs) for HCC development of 1.19 [95\% confidence interval $(\mathrm{CI})=1.12-1.27], 1.40$ (95\% $\mathrm{CI}=1.25-1.56)$, and 1.81 (95\% $\mathrm{CI}=1.50-2.19)$ were associated with alcohol consumption of 25,50 and $100 \mathrm{~g} /$ day, respectively. This indicates that the risk of HCC development is proportional to the amount of alcohol consumed, although the risk in those who consume low or moderate levels remains unclear (25).

\section{NAFLD and NASH}

NAFLD is characterized by liver steatosis without a history of significant alcohol use or liver disease of unknown etiology (26). NAFLD is the most common cause of chronic liver disease worldwide and it is a hepatic manifestation of the metabolic syndrome, which is a constellation of problems that includes hypertension, obesity, insulin resistance and dyslipidemia (26). The prevalence of NAFLD increases with age, however, it has been described in persons of all ages (27). The prevalence of NAFLD and its related complications is expected to increase in the future (28).

The prevalence of NAFLD is reported to range from 10 to $30 \%$ in adults and its prevalence is increasing in Japan as well as in Western countries, because of the epidemic rise in DM and obesity (29). NASH is part of the spectrum of NAFLD and it is a severe form of NAFLD. Approximately $10 \%$ of patients with NAFLD progress to NASH and $20 \%$ of NASH cases can slowly progress to liver cirrhosis and even HCC $(13,30)$. Powell et al reported the first case of NASH-related HCC (31). Since then, several case series of NASH-related HCC have been reported and it has attracted the attention of oncologists $(32,33)$. The majority of CC cases are thought to be end-stage NASH because several clinical features such as obesity and DM in patients with CC are associated with NASH. However, histological findings often are not informative when liver cirrhosis is already established because it is hypothesized that CC often represents 'burned out' NASH $(34,35)$. Thus, the impact of NASH on the incidence of liver cirrhosis and HCC may be underestimated. Marrero et al reported that $20 \%$ of patients in the cryptogenic liver disease group had evidence of NASH on liver biopsies prior to HCC occurrence (14). In addition, half of the patients with $\mathrm{CC}$ had prior NASH or suspected NAFLD and they concluded that NAFLD was the underlying liver disease in $13 \%$ of patients with HCC.

The natural history and prognosis of NASH remains elusive, because there are few data from prospective cohort studies (36). Ashca et al reported that yearly cumulative incidence of HCC was $2.6 \%$ in patients with NASH-related cirrhosis $(n=195)$, compared with $4.0 \%$ in patients with HCV-related cirrhosis $(n=315)$ (37). Likewise, Yatsuji et al conducted a comparative study between 68 patients with NASH-related cirrhosis and 69 with HCV-related cirrhosis, to clarify the incidence of HCC and clinical outcomes (38). They reported that the 5-year rate of HCC development was $11.3 \%$ for NASH-related cirrhosis and $30.5 \%$ for $\mathrm{HCV}$-related cirrhosis, and the 5-year survival rates were $75.2 \%$ for NASH-related cirrhosis and $73.8 \%$ for $\mathrm{HCV}$-related cirrhosis. The hepatocarcinogenesis rate in patients with NASH-related cirrhosis is considered to be lower than that in patients with HCV-related cirrhosis.
Metabolic syndrome is reported to be associated with development of HCC and intrahepatic cholangiocarcinoma (ICC). A population-based study from the US comprising 3,649 HCC cases, 743 ICC cases and 195,953 comparative persons demonstrated that metabolic syndrome was significantly more common among persons who developed HCC (37.1\%) and ICC (29.7\%) than in the comparison group (17.1\%). After adjusted multiple logistic regression analyses, metabolic syndrome remained significantly associated with increased risk of $\mathrm{HCC}(\mathrm{HR}=2.13$; 95\% $\mathrm{CI}=1.96-2.31)$ and $\mathrm{ICC}(\mathrm{HR}=1.56$; 95\% CI=1.32-1.83) (39).

\section{DM}

El-Serag et al conducted a large longitudinal study comprising 173,643 patients with DM and 650,620 without DM (98\% male) to elucidate an association between DM and chronic liver disease and/or HCC (41). They demonstrated that DM was associated with an HR of 1.98 (95\% CI=1.88-2.09) for chronic non-alcoholic liver disease and an HR of 2.16 (95\% CI=1.86-2.52) for HCC development (40). Furthermore, Wang et al recently conducted a meta-analysis including a total of 25 cohort studies to examine the relationship between DM and HCC (41). They reported that $\mathrm{DM}$ was associated with an increased incidence of $\mathrm{HCC}(\mathrm{HR}=2.01,95 \% \mathrm{CI}=1.61-2.51)$, compared with individuals without $\mathrm{DM}$ and it was also positively associated with HCC mortality ( $\mathrm{HR}=1.56,95 \% \mathrm{CI}=1.30-1.87)$. Thus, DM was demonstrated to be an independent risk factor for progression of chronic liver disease and HCC development.

Up to $70 \%$ of patients with type II DM have some degree of fatty liver disease (42). About $10 \%$ of patients with liver cirrhosis have overt DM and a larger percentage of patients have impaired glucose tolerance (43). DM may be the result of liver cirrhosis, because in patients with liver cirrhosis, insulin is not cleared properly (44).

El-Serag et al conducted a matched case-control study comprising 1,303 cases with DM and 5,212 controls to investigate the effect of statins on HCC development. The adjusted HR for statin reduction of HCC development was 0.74 (95\% CI=0.64-0.87) and they concluded that statin use is associated with a significant reduction in the risk of HCC in patients with DM (45).

\section{Obesity}

Up to $90 \%$ of obese individuals have some degree of chronic fatty liver disease and hepatic steatosis correlated significantly with increasing BMI $(42,46)$. Obesity and related metabolic abnormalities, including chronic inflammatory conditions, increase the risk of HCC development. Dysregulation of tumor necrosis factor- $\alpha$ and interleukin- 6 expressed in adipose tissue, which are essential cancer promoters in inflammation-related carcinogenesis, is associated with the development of steatosis and liver inflammation. These cytokines are also pivotal in the development of obesity-related HCC (47).

Obesity is reported to be linked to HCC development and HCC patients with obesity may have worsened clinical outcomes $(16,48)$. Based on the prevalence of HCC, it was estimated that $28 \%$ of male $\mathrm{HCC}$ cases and $27 \%$ of female cases were due to overweight or obesity (49). Calle et al indicated that 
obesity is associated with significantly increased HCC death rates with an $\mathrm{HR}$ of 4.52 in patients with $\mathrm{BMI}>35 \mathrm{~kg} / \mathrm{m} 2$ (16). Another large population-based study from Denmark demonstrated in $>40,000$ obese patients that the HR of developing liver cancer was increased to 1.9 compared with the general population (50). Likewise, the Korea National Health Insurance Corporation Study reported that there was an HR of 1.53 for development of HCC in men with BMI $>30 \mathrm{~kg} / \mathrm{m}^{2}$ as compared with normal controls, even after controlling for $\mathrm{HBV}$ infection, which is the most common cause of HCC in Korea (51).

\section{Iron}

Liver iron overload is suspected when the levels of serum iron and ferritin are high. In patients with hepatitis virus infection, iron overload, which is distinct from hereditary hemochromatosis, is associated with poor prognosis (52). Furthermore, Sorrentino et al measured hepatic iron retrospectively in liver biopsies of 153 patients with NASH-related cirrhosis (51 with HCC and 102 controls without HCC) (53). They reported that iron deposits were more frequent in HCC patients than in controls and the median corrected total iron score was significantly higher in HCC patients. Excessive alcohol consumption and iron overload may act in synergy to promote liver fibrosis and carcinogenesis (54). Ioannou et al demonstrated that elevated serum transferriniron saturation is associated with an increased incidence of liver cirrhosis or HCC; particularly in patients with heavy alcohol consumption (54). Liver iron overload may be associated with the progression of liver disease and the development of HCC in patients with underlying liver disease of various etiologies. Iron overload is not a benign condition regardless of etiology, and when recognized, surveillance for HCC and adequate therapy for reducing iron overload should be undertaken.

\section{Other causes}

$P B C$. There are several reports of NBNC-HCC with other causes than alcohol or NAFLD/NASH. According to the Japanese national data of patients with PBC, the HCC incidence was $2.4 \%(71 / 2946)$ and the HCC incidence according to sex was $5.1 \%(19 / 370)$ in men and 2.0\% (52/2576) in women (55). Multivariate analysis of risk factors associated with PBC-related HCC development according to sex revealed histological fibrosis stage at the time of PBC diagnosis as an independent risk factor in women, but not in men (55). The authors concluded that male PBC patients should be particularly carefully screened for HCC from the early stages of PBC.

$A I H$. Although the clinical outcome in patients with AIH is generally good, there have been several patients with AIH who developed HCC (56). The National Hospital Organization Liver Network Study Group in Japan reported in 193 AIH patients that seven (3.6\%) developed HCC during follow-up, and the presence of liver cirrhosis at presentation was an independent risk factor for $\mathrm{HCC}$ in patients with $\mathrm{AIH}$.

$P S C$. PSC is a chronic inflammatory disease involving the biliary tract. PSC can lead to liver cirrhosis due to persistent inflammation in the liver, therefore, it is not surprising that PSC-related cirrhosis can develop into HCC. The risk of HCC development in PSC patients with liver cirrhosis is estimated to be up to $2 \%$ per year (57). However, the incidence of HCC for patients with PSC has not been fully studied (58).

Hereditary hemochromatosis and Wilson disease. Hereditary hemochromatosis is one of the most common autosomal recessive genetic disorders. It is caused by mutations in the HFE gene and/or other mutations in the iron metabolism system and is characterized by excess iron absorption and storage in the liver $(59,60)$. Several population-based and case-control studies have demonstrated that hereditary hemochromatosis markedly elevates the risk of HCC (61-64). A large population-based study from Sweden demonstrated that patients with hereditary hemochromatosis had a 20-fold increased risk of $\mathrm{HCC}(\mathrm{HR}=21$, $95 \% \mathrm{CI}=16-22)$ but an almost unaltered risk of all other cancers $(\mathrm{HR}=1.2,95 \% \mathrm{CI}=1.0-1.4)$ (64).

Wilson disease is an autosomal recessive disorder of copper metabolism (65). A nationwide survey to examine the etiology of liver cirrhosis in Japan found Wilson disease in two (0.01\%) of 16,117 patients with liver cirrhosis and HCC (66). Liver cirrhosis is a well-recognized complication of Wilson disease, but HCC is extremely rare (66).

Budd-Chiari syndrome. BCS is a rare hepatic disease caused by occlusion of the hepatic venous outflow. Several reports indicate that hepatic congestion caused by obstruction of hepatic venous outflow can lead to liver cirrhosis and even HCC $(67,68)$. A meta-analysis from China including 16 studies in patients with BCS revealed that the prevalence of $\mathrm{HCC}$ in BCS was 2.0-46.2\% in 12 Asian studies, 40.0-51.6\% in two African studies, $11.3 \%$ in one European study and $11.1 \%$ in one American study (69). These results suggest that the prevalence of HCC in patients with BCS varies depending on geographical location. However, because a relatively high incidence of HCC in patients with BCS was observed in each study, routine radiological surveillance for HCC is warranted in patients with BCS.

$O B I$. In a small proportion of individuals, detectable HBV DNA in the serum and/or liver is observed in the absence of circulating hepatitis B surface antigen (HBsAg) (70-72). OBI is defined by the presence of HBV DNA in the liver tissue of individuals who test negative for $\mathrm{HBsAg}$, regardless of the detection of HBV DNA in the serum. The clinical implications of OBI involve causing cryptogenic liver disease and contributing to the progression of liver disease or even $\operatorname{HCC}(71,73)$. OBI may maintain direct mechanisms of HBV-related carcinogenesis via the ability to integrate into the host genome, and production of transforming proteins including mainly $\mathrm{X}$ and preS-S proteins (73-75). In addition, OBI may exert pro-oncogenic properties through indirect mechanisms $(72,74,75)$. These are associated with its propensity to induce persistent necroinflammation in the liver and to promote the progression of chronic hepatitis to liver cirrhosis. This indicates the step preceding HCC occurrence in the majority of cases.

Aflatoxins. Aflatoxins are naturally occurring mycotoxins produced by Aspergillus species. They commonly contaminate foods such as grain, peanuts and corn, and aflatoxin exposure is reported to elevate the risk of HCC (76). Chen et al conducted a community-based cohort study combined with 
molecular dosimetry of aflatoxin exposure to elucidate the relationship between the risk of HCC development and aflatoxins (77). Elevated aflatoxin exposure measured by detectable aflatoxin B1-albumin adducts was an independent risk factor for $\mathrm{HCC}$ development after adjusting for important confounders $(\mathrm{HR}=5.5,95 \% \mathrm{CI}=1.2-24.5)$. However, in Japan, aflatoxin-associated $\mathrm{HCC}$ is extremely rare (7).

\section{Mechanism of carcinogenesis in NBNC-HCC}

Although the detailed mechanism of liver carcinogenesis in patients with NBNC chronic liver disease remains elusive, insulin resistance and oxidative stress may be involved, especially in patients with NASH. NASH is characterized by insulin resistance with hyperinsulinemia, and the insulin resistance is reported to be associated with liver carcinogenesis (26,78). Insulin-like growth factor (IGF)-1 significantly activates mitogen-activated protein kinase, and increases overexpression of the c-Fos and c-Jun proto-oncogenes in cultured hepatoma cells, and IGF-1 is potentially involved in the development of HCC (78-82). c-Jun N-terminal kinase (JNK)1 has also recently attracted attention because it is linked with obesity, insulin resistance, NASH and HCC. Obesity is linked to abnormal elevation of JNK activity (83). In addition, Puri et al reported that JNK activation increases hepatic inflammation and apoptosis (84). JNK1 may thus be the most essential kinase that is upregulated in HCC.

Adipose tissue is thought to be an endocrine organ because of its ability to secrete adipokines such as adiponection and leptin (85). Adiponectin and leptin are related to insulin resistance and obesity $(85,86)$. Adiponectin has emerged as the most abundant circulating adipocytokine and is an anti-inflammatory polypeptide in adipose tissue (85). It is decreased in the presence of insulin resistance and inhibits angiogenesis through modulation of apoptosis in animal models (87). Severe liver steatosis and fibrosis are found in adiponectin knockout mice as compared with wild-type mice (86). In addition, liver adenoma and hyperplastic nodules develop within the liver in adiponectin knockout mice, whereas no tumor formation is found in wildtype mice (86). These observations suggest that adiponectin is inversely associated with liver disease progression. Leptin is the product of the obese gene and is mainly produced by adipose tissue, and promotes angiogenesis and mediates the progression of NASH to HCC in animal models $(88,89)$. Leptin-mediated neovascularization, which coordinates with vascular endothelial growth factor, may accelerate liver fibrosis and cause liver carcinogenesis in patients with NASH, although its role in NAFLD or NASH is still unclear $(88,89)$.

In NAFLD patients, mitochondrial dysfunction also leads to free radical production and oxidative stress, which may provide the 'second hit' that allows progression from steatosis to steatohepatitis, liver cirrhosis and even HCC (90). NASH-related insulin resistance causes inhibition of liver mitochondrial fatty acid oxidation, and increased intracellular fatty acids can lead to oxidative DNA damage via stimulating microsomal peroxidases (91). Oxidative stress may also promote carcinogenesis (92). Insulin resistance, hepatic steatosis, oxidative stress and imbalances in adipokines/cytokines interplay, which are the most essential factors involved in NAFLD pathogenesis and progression, could also have a pivotal role in liver carcinogenesis, through DNA damage and promoting cellular growth $(90,93,94)$. In HCC patients with obesity, these correlations indicate a possible association between the metabolic syndrome and poor clinical outcomes.

Reactive oxygen species (ROS) can also activate fibrosis (90). Ishii et al demonstrated in animal models that eicosapentaenoic acid (EPA) improved steatohepatitis with decreasing serum ROS, which is associated with inhibited development of HCC (95). Treatment with EPA may minimize the risk of HCC development in patients with NASH. However, there are few promising drugs with the potential to reduce the risk of HCC development in patients with NASH.

Overall, obesity and insulin resistance are known to be related significantly to hepatic steatosis (96). Increased levels of hepatic steatosis are linked to more severe necroinflammatory activity and liver fibrosis, and several studies reported that the increase in steatosis may be a predictor for liver fibrosis progression $(46,97,98)$. Subsequently, liver disease occurs more frequently in patients with more severe metabolic disorders, possibly leading to a higher rate of development of HCC.

\section{Clinicopathological features and prognosis in patients with NBNC-HCC}

Several studies have investigated the clinicopathological features of NBNC-HCC. Takuma et al reviewed 11 patients with NASH-associated HCC (6 male, 5 female; mean age, 73.8 years) who received curative treatment (99). They reported that most (91\%) patients were diagnosed with obesity, DM, hypertension or dyslipidemia, and 7 patients (64\%) also had a non-cirrhotic liver. Duan et al reported 169 patients with NAFLD-associated HCC (68 with non-cirrhotic liver and 101 with cirrhosis); $72.8 \%$ were male with a median age at abnormal liver function tests and diagnosis of NAFLD and HCC of 60, 64 and 67 years, respectively (100). Most patients had obesity (75\%) and DM (59.8\%), 32.3\% had dyslipidemia, and 53\% had hypertension. Nearly all patients were complicated with at least one metabolic disorder. In terms of tumor characteristics, the majority $(76 \%)$ of the HCC patients had a solitary tumor nodule $0.8-20 \mathrm{~cm}$ in diameter (mean $3.4 \mathrm{~cm}$ ) and most (61.1\%) patients had moderately differentiated HCC. Reddy et al compared 52 patients with NASH-related HCC and 162 with HCV and/or alcohol-related HCC (101). NASH-related HCC patients were older, more often female, had higher BMI at HCC diagnosis, and more frequently had DM, dyslipidemia and the metabolic syndrome. Liver function at presentation was worse in patients with HCV/alcohol-related HCC.

Whether patients with NBNC-HCC have comparable prognosis to patients with $\mathrm{HCC}$ with other causes remains controversial. In a single-center retrospective study of patients with a maximum tumor size $<5 \mathrm{~cm}$, who received curative surgery, Kaibori et al reported that patients with NBNC-HCC tended to have a higher overall survival rate than those with $\mathrm{HCV}$-related HCC (8). Patients with NBNC-HCC had a significantly higher disease-free survival rate than those with HCV-related HCC, although the difference in overall and disease-free survival between the two groups was not significant.

In a large retrospective comparative study, Li et al investigated 675 patients with NBNC-HCC and 3529 with hepatitis B surface antigen-positive/HCV-antibody-negative HCC who 


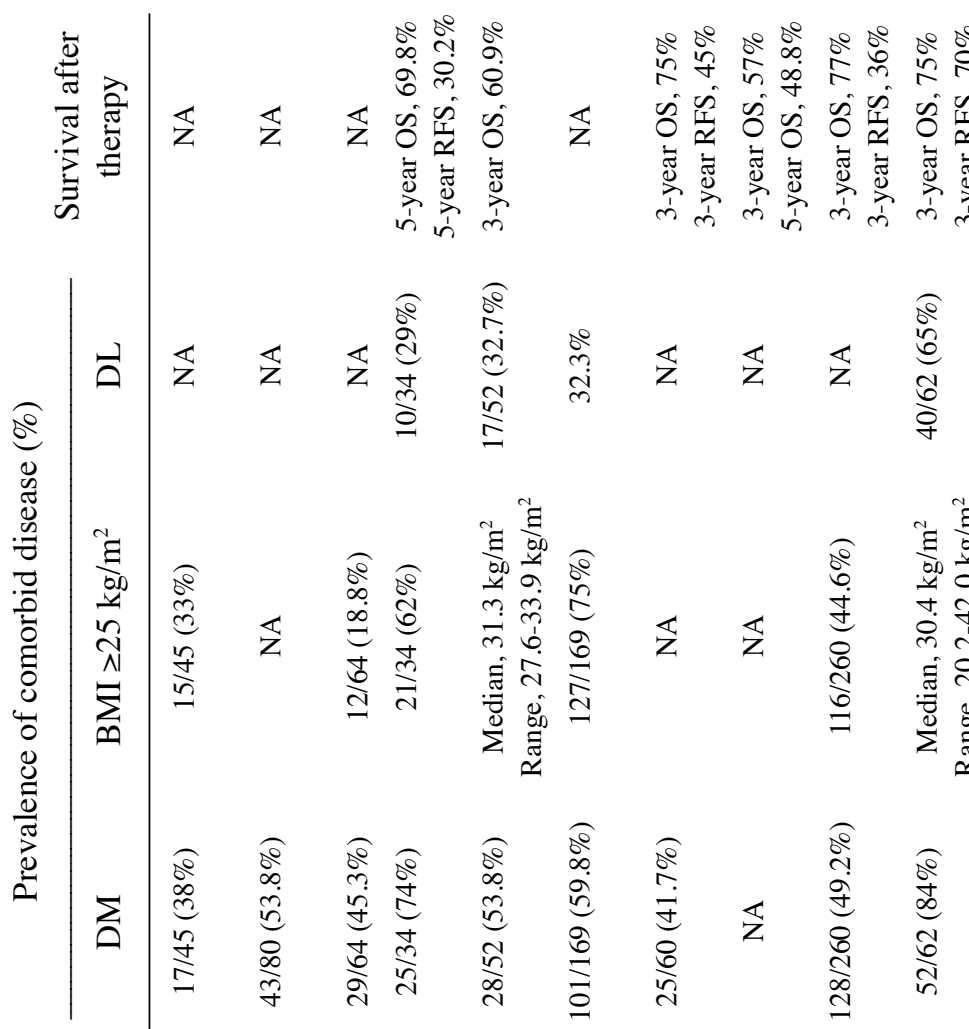

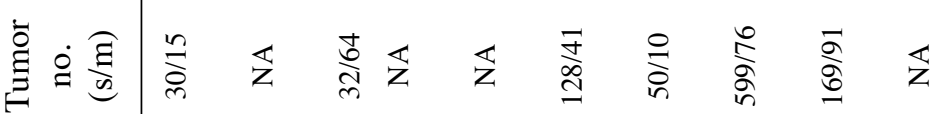

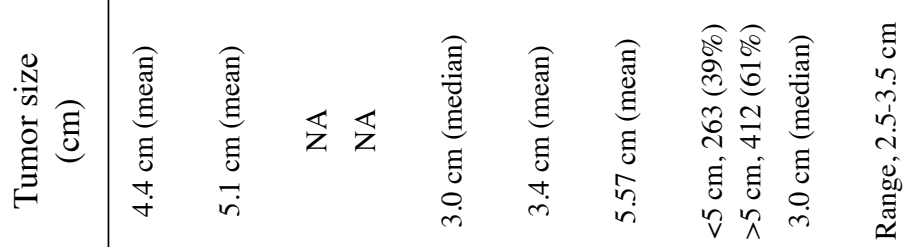

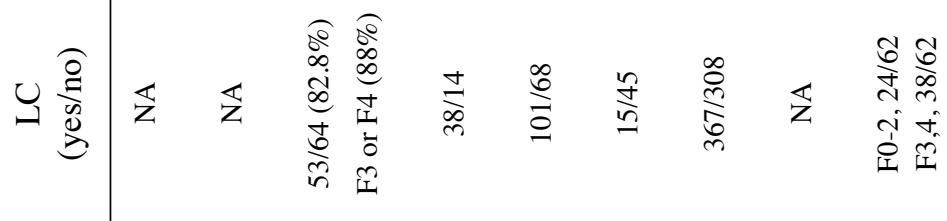

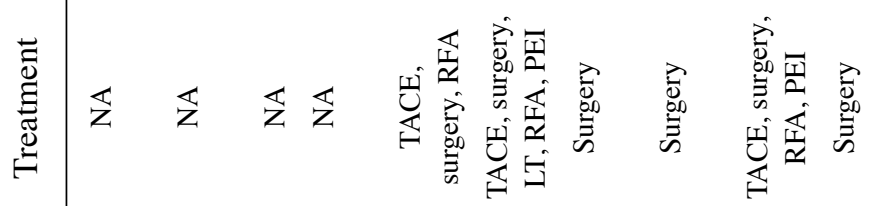

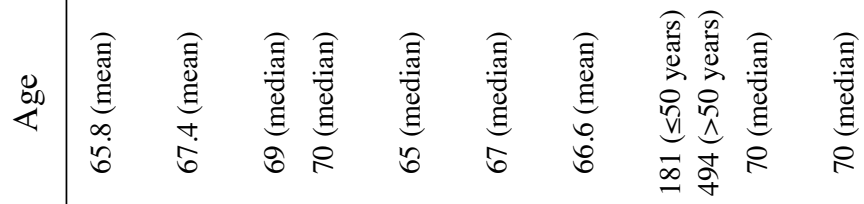

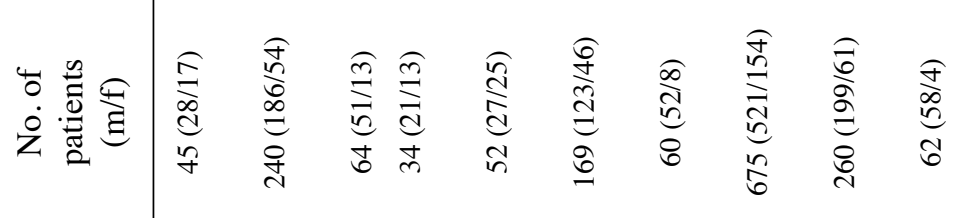


underwent curative resection (102). There were no significant differences between the two groups regarding overall survival, cumulative incidence of HCC-specific death and recurrence. Furthermore, in their multivariate analysis they found that female sex, serum $\gamma$-glutamyl transpeptidase level, tumor size, tumor capsule and tumor differentiation were independent risk factors associated with HCC-specific survival in patients with NBNC-HCC. They also claimed that women with NBNC-HCC should be closely monitored even after curative surgery.

Malik et al reported in a single-center prospective study that survival after liver transplantation in patients with HCC and NASH-related liver cirrhosis was $88 \%$, with a mean followup of 2.5 years (103). There was no significant difference in 5-year survival between patients transplanted for NASHrelated liver cirrhosis with and without HCC. There was no significant difference in 5-year survival after liver transplantation between HCC patients with and without NASH-related cirrhosis. They therefore concluded that patients with NASH and HCC have a favorable clinical outcome after liver transplantation.

Giannini et al demonstrated that $\mathrm{HCC}$ patients with $\mathrm{CC}$ had a significantly greater prevalence of advanced HCC stage, lower amenability to any treatment, and shorter survival compared with HCV-related HCC patients (104). This was because HCC in patients with $\mathrm{CC}$ is often diagnosed at an advanced stage owing to the lack of imaging surveillance systems.

Tokushige et al conducted prospective studies to clarify the outcomes and recurrence of HCC in NASH, compared with patients with HCV-related HCC (105). The 5-year survival rate was $55.2 \%$ and cumulative recurrence of $\mathrm{HCC}$ at 5 years was $69.8 \%$ in treated NASH-HCC, and both groups showed similar survival and recurrence rates.

Overall, owing to the lack of adequate surveillance of $\mathrm{HCC}$ in patients with NBNC liver disease, NBNC-HCC tends to be diagnosed at an advanced stage. However, in NBNC-HCC patients who undergo curative therapy, clinical outcomes after HCC therapy in NBNC-HCC patients are comparable or even better than those in patients with hepatitis-related HCC. Previous reports of clinical characteristics and clinical outcomes in patients with NBNC-HCC are summarized in Table I.

\section{Conclusion}

Various factors unrelated to hepatitis virus are implicated in the development of HCC. Cumulative evidence suggests that NAFLD and NASH, which are hepatic manifestations of the metabolic syndrome that includes hypertension, obesity, insulin resistance and hyperlipidemia, can progress to cirrhosis and HCC. Obesity or DM itself can be an independent risk factor for the development of HCC. Insulin resistance, oxidative stress and adipokines are closely associated with liver carcinogenesis. Most patients with NBNC-HCC may have at least one metabolic disorder. Owing to the lack of adequate surveillance of NBNC-HCC, HCC tends to be diagnosed at an advanced stage. However, in NBNC-HCC patients who undergo curative therapy, clinical outcomes after HCC therapy in NBNC-HCC patients may be comparable or even better than in patients with hepatitis-related HCC. Furthermore, the ability to decide which patients with liver disease with non-viral causes will develop HCC will have screening implications in the future.

\section{Acknowledgements}

The authors would like to thank all the staff in their hospital for their valuable support.

\section{References}

1. Livraghi T, Mäkisalo H and Line PD: Treatment options in hepatocellular carcinoma today. Scand J Surg 100: 22-29, 2011.

2. El-Serag HB: Epidemiology of viral hepatitis and hepatocellular carcinoma. Gastroenterology 142: 1264-1273, 2012.

3. De Lope CR, Tremosini S, Forner A, Reig M and Bruix J: Management of HCC. J Hepatol 56 (Suppl 1): S75-S87, 2012.

4. Nishikawa H, Osaki Y, Iguchi E, Takeda H, Matsuda F, Nakajima J, Sakamoto A, Hatamaru K, Saito S, Nasu A, Kita R and Kimura T: Radiofrequency ablation for hepatocellular carcinoma: the relationship between a new grading system for the ablative margin and clinical outcomes. J Gastroenterol: Oct 12, 2012 (Epub ahead of print).

5. Nishikawa H, Arimoto A, Wakasa T, Kita R, Kimura T and Osaki Y: Surgical resection for hepatocellular carcinoma: clinical outcomes and safety in elderly patients. Eur J Gastroenterol Hepatol 25: 912-919, 2013.

6. Umemura T, Ichijo T, Yoshizawa K, Tanaka E and Kiyosawa K: Epidemiology of hepatocellular carcinoma in Japan. J Gastroenterol 44 (Suppl 19): 102-107, 2009.

7. Tokushige K, Hashimoto E, Horie Y, Taniai M and Higuchi S: Hepatocellular carcinoma in Japanese patients with nonalcoholic fatty liver disease, alcoholic liver disease, and chronic liver disease of unknown etiology: report of the nationwide survey. J Gastroenterol 46: 1230-1237, 2011.

8. Kaibori M, Ishizaki M, Matsui K and Kwon AH: Clinicopathologic characteristics of patients with non-B non- $\mathrm{C}$ hepatitis virus hepatocellular carcinoma after hepatectomy. Am J Surg 204: 300-307, 2012.

9. Abe H, Yoshizawa K, Kitahara T, Aizawa R, Matsuoka M and Aizawa Y: Etiology of non-B non-C hepatocellular carcinoma in the eastern district of Tokyo. J Gastroenterol 43: 967-974, 2008.

10. Nagaoki Y, Hyogo H, Aikata H, Tanaka M, Naeshiro N, Nakahara T, Honda Y, Miyaki D, Kawaoka T, Takaki S, Hiramatsu A, Waki K, Imamura M, Kawakami Y, Takahashi S and Chayama K: Recent trend of clinical features in patients with hepatocellular carcinoma. Hepatol Res 42: 368-375, 2012.

11. Suzuki Y, Ohtake T, Nishiguchi S, Hashimoto E, Aoyagi Y, Onji M and Kohgo Y; The Japan Non-B, Non-C Liver Cirrhosis Study Group: Survey of non-B, non-C liver cirrhosis in Japan. Hepatol Res: Dec 26, 2012 (Epub ahead of print).

12. Kim SK, Marusawa H, Eso Y, Nishikawa H, Ueda Y, Kita R, Kimura T, Chiba T, Osaki Y and Kudo M: Clinical characteristics of non-B non-C hepatocellular carcinoma: a single-center retrospective study. Digestion 84 (Suppl 1): 43-49, 2011.

13. Bugianesi E, Leone N, Vanni E, Marchesini G, Brunello F, Carucci P, Musso A, De Paolis P, Capussotti L and Salizzoni M: Expanding the natural history of nonalcoholic steatohepatitis: from cryptogenic cirrhosis to hepatocellular carcinoma. Gastroenterology 123: 134-140, 2002.

14. Marrero JA, Fontana RJ, Su GL, Conjeevaram HS, Emick DM and Lok AS: NAFLD may be a common underlying liver disease in patients with hepatocellular carcinoma in the United States. Hepatology 36: 1349-1354, 2002.

15. Torres DM and Harrison SA: Nonalcoholic steatohepatitis and noncirrhotic hepatocellular carcinoma: fertile soil. Semin Liver Dis 32: 30-38, 2012.

16. Calle EE, Rodriguez $\mathrm{C}$, Walker-Thurmond $\mathrm{K}$ and Thun MJ: Overweight, obesity, and mortality from cancer in a prospectively studied cohort of US adults. N Engl J Med 348: 1625-1638, 2003.

17. Kaji K, Yoshiji H, Ikenaka Y, Noguchi R, Aihara Y, Shirai Y, Douhara A and Fukui H: Possible involvement of angiogenesis in chronic liver diseases: interaction among renin-angiotensinaldosterone system, insulin resistance and oxidative stress. Curr Med Chem 19: 1889-1898, 2012.

18. Yasui K, Hashimoto E, Tokushige K, Koike K, Shima T, Kanbara Y, Saibara T, Uto H, Takami S, Kawanaka M, Komorizono Y and Okanoue T; The Japan NASH Study Group: Clinical and pathological progression of non-alcoholic steatohepatitis to hepatocellular carcinoma. Hepatol Res 42: 767-773, 2012. 
19. Chung $\mathrm{H}$, Ueda $\mathrm{T}$ and Kudo $\mathrm{M}$ : Changing trends in hepatitis $\mathrm{C}$ infection over the past 50 years in Japan. Intervirology 53: 39-43, 2010.

20. Schaefer EA and Chung RT: Anti-hepatitis $C$ virus drugs in development. Gastroenterology 142: 1340-1350, 2012.

21. Jacobson IM, Pawlotsky JM, Afdhal NH, Dusheiko GM, Forns X, Jensen DM, Poordad F and Schulz J: A practical guide for the use of boceprevir and telaprevir for the treatment of hepatitis C. J Viral Hepat 19 (Suppl 2): 1-26, 2012.

22. Rosen HR: Clinical practice. Chronic hepatitis C infection. N Engl J Med 364: 2429-2438, 2011.

23. Ertle J, Dechêne A, Sowa JP, Penndorf V, Herzer K, Kaiser G, Schlaak JF, Gerken G, Syn WK and Canbay A: Non-alcoholic fatty liver disease progresses to hepatocellular carcinoma in the absence of apparent cirrhosis. Int J Cancer 128: 2436-2443, 2011

24. Donato F, Tagger A, Gelatti U, Parrinello G, Boffetta P, Albertini A, Decarli A, Trevisi P, Ribero ML, Martelli C, Porru S and Nardi G: Alcohol and hepatocellular carcinoma: the effect of lifetime intake and hepatitis virus infections in men and women. Am J Epidemiol 155: 323-331, 2002.

25. Corrao G, Bagnardi V, Zambon A and La Vecchia C: A metaanalysis of alcohol consumption and the risk of 15 diseases. Prev Med 38: 613-619, 2004.

26. Sookoian S and Pirola CJ: The genetic epidemiology of nonalcoholic fatty liver disease: toward a personalized medicine. Clin Liver Dis 16: 467-485, 2012.

27. Shen L, Fan JG, Shao Y, Zeng MD, Wang JR, Luo GH, Li JQ and Chen SY: Prevalence of nonalcoholic fatty liver among administrative officers in Shanghai: an epidemiological survey. World J Gastroenterol 9: 1106-1110, 2003.

28. Ong JP and Younossi ZM: Epidemiology and natural history of NAFLD and NASH. Clin Liver Dis 11: 1-16, 2007.

29. Kojima S, Watanabe N, Numata M, Ogawa T and Matsuzaki S: Increase in the prevalence of fatty liver in Japan over the past 12 years: analysis of clinical background. J Gastroenterol 38: 954-961, 2003

30. Harrison SA, Torgerson S and Hayashi PH: The natural history of nonalcoholic fatty liver disease: a clinical histopathological study. Am J Gastroenterol 98: 2042-2047, 2003.

31. Powell EE, Cooksley WG, Hanson R, Searle J, Halliday JW and Powell LW: The natural history of nonalcoholic steatohepatitis: a follow-up study of forty-two patients for up to 21 years. Hepatology 11: 74-80, 1990

32. Hashimoto E, Yatsuji S, Tobari M, Taniai M, Torii N, Tokushige $\mathrm{K}$ and Shiratori K: Hepatocellular carcinoma in patients with nonalcoholic steatohepatitis. J Gastroenterol 44 (Suppl 19): 89-95, 2009.

33. Hashizume H, Sato K, Takagi H, Hirokawa T, Kojima A, Sohara N, Kakizaki S, Mochida Y, Shimura T and Sunose Y: Primary liver cancers with nonalcoholic steatohepatitis. Eur J Gastroenterol Hepatol 19: 827-834, 2007.

34. Yoshioka Y, Hashimoto E, Yatsuji S, Kaneda H, Taniai M, Tokushige $\mathrm{K}$ and Shiratori K: Nonalcoholic steatohepatitis: cirrhosis, hepatocellular carcinoma, and burnt-out NASH. J Gastroenterol 39: 1215-1218, 2004.

35. Ayata G, Gordon FD, Lewis WD, Pomfret E, Pomposelli JJ, Jenkins RL and Khettry U: Cryptogenic cirrhosis: clinicopathologic findings at and after liver transplantation. Hum Pathol 33: 1098-1104, 2002.

36. Starley BQ, Calcagno CJ and Harrison SA: Nonalcoholic fatty liver disease and hepatocellular carcinoma: a weighty connection. Hepatology 51: 1820-1832, 2010.

37. Ascha MS, Hanouneh IA, Lopez R, Tamimi TA, Feldstein AF and Zein NN: The incidence and risk factors of hepatocellular carcinoma in patients with nonalcoholic steatohepatitis. Hepatology 51: 1972-1978, 2010.

38. Yatsuji S, Hashimoto E, Tobari M, Taniai M, Tokushige $\mathrm{K}$ and Shiratori K: Clinical features and outcomes of cirrhosis due to non-alcoholic steatohepatitis compared with cirrhosis caused by chronic hepatitis C. J Gastroenterol Hepatol 24: 248-254, 2009.

39. Welzel TM, Graubard BI, Zeuzem S, El-Serag HB, Davila JA and McGlynn KA: Metabolic syndrome increases the risk of primary liver cancer in the United States: a study in the SEERMedicare database. Hepatology 54: 463-471, 2011.

40. El-Serag HB, Tran T and Everhart JE: Diabetes increases the risk of chronic liver disease and hepatocellular carcinoma. Gastroenterology 126: 460-468, 2004.

41. Wang C, Wang X, Gong G, Ben Q, Qiu W, Chen Y, Li G and Wang L: Increased risk of hepatocellular carcinoma in patients with diabetes mellitus: a systematic review and meta-analysis of cohort studies. Int J Cancer 130: 1639-1648, 2012.
42. Neuschwander-Tetri BA and Caldwell SH: Nonalcoholic steatohepatitis: summary of an AASLD Single Topic Conference. Hepatology 37: 1202-1219, 2003.

43. Garcia-Compean D, Jaquez-Quintana JO, GonzalezGonzalez JA and Maldonado-Garza H: Liver cirrhosis and diabetes: risk factors, pathophysiology, clinical implications and management. World J Gastroenterol 15: 280-288, 2009.

44. Allison ME, Wreghitt T, Palmer CR and Alexander GJ: Evidence for a link between hepatitis $\mathrm{C}$ virus infection and diabetes mellitus in a cirrhotic population. J Hepatol 21: 1135-1139, 1994.

45. El-Serag HB, Johnson ML, Hachem C and Morgana RO: Statins are associated with a reduced risk of hepatocellular carcinoma in a large cohort of patients with diabetes. Gastroenterology 136: 1601-1608, 2009.

46. Ohata K, Hamasaki K, Toriyama K, Matsumoto K, Saeki A, Yanagi K, Abiru S, Nakagawa Y, Shigeno M, Miyazoe S, Ichikawa T, Ishikawa H, Nakao K and Eguchi K: Hepatic steatosis is a risk factor for hepatocellular carcinoma in patients with chronic hepatitis C virus infection. Cancer 97: 3036-3043, 2003.

47. Shimizu M, Tanaka T and Moriwaki H: Obesity and hepatocellular carcinoma: targeting obesity-related inflammation for chemoprevention of liver carcinogenesis. Semin Immunopathol 35: 191-202, 2013.

48. Bianchini F, Kaaks R and Vainio H: Overweight, obesity, and cancer risk. Lancet Oncol 3: 565-574, 2002.

49. Larsson SC and Wolk A: Overweight, obesity and risk of liver cancer: a meta-analysis of cohort studies. Br J Cancer 97: 1005-1008, 2007.

50. Moller H, Mellemgaard A, Lindvig K and Olsen JH: Obesity and cancer risk: a Danish record-linkage study. Eur J Cancer 30A: 344-350, 1994.

51. Oh SW, Yoon YS and Shin SA: Effects of excess weight on cancer incidences depending on cancer sites and histologic findings among men: Korea National Health Insurance Corporation Study. J Clin Oncol 23: 4742-4754, 2005.

52. Drakesmith $\mathrm{H}$ and Prentice A: Viral infection and iron metabolism. Nat Rev Microbiol 6: 541-552, 2008.

53. Sorrentino P, D'Angelo S, Ferbo U, Micheli P, Bracigliano A and Vecchione R: Liver iron excess in patients with hepatocellular carcinoma developed on non-alcoholic steato-hepatitis. J Hepatol 50: 351-357, 2009.

54. Ioannou GN, Weiss NS and Kowdley KV: Relationship between transferrin-iron saturation, alcohol consumption, and the incidence of cirrhosis and liver cancer. Clin Gastroenterol Hepatol 5: 624-629, 2007.

55. Harada K, Hirohara J, Ueno Y, Nakano T, Kakuda Y, Tsubouchi H, Ichida T and Nakanuma Y: Incidence of and risk factors for hepatocellular carcinoma in primary biliary cirrhosis: national data from Japan. Hepatology 57: 1942-1949, 2013.

56. Migita K, Watanabe Y, Jiuchi Y, Nakamura Y, Saito A, Yagura M, Ohta H, Shimada M, Mita E, Hijioka T, Yamashita H, Takezaki E, Muro T, Sakai H, Nakamuta M, Abiru S, Komori A, Ito M, Yatsuhashi H, Nakamura M and Ishibashi H; Japanese NHO-Liver-network study group: Hepatocellular carcinoma and survival in patients with autoimmune hepatitis (Japanese National Hospital Organization-autoimmune hepatitis prospective study). Liver Int 32: 837-844, 2012.

57. Harnois DM, Gores JG, Ludwig J, Steers JL, LaRusso NE and Wiesner RH: Are patients with cirrhotic stage primary sclerosing cholangitis at risk for the development of hepatocellular cancer? J Hepatol 27: 512-516, 1997.

58. Razumilava N, Gores GJ and Lindor KD: Cancer surveillance in patients with primary sclerosing cholangitis. Hepatology 54 : 1842-1852, 2011.

59. Edwards CQ, Griffen LM, Goldgar D, Drummond C, Skolnick MH and Kushner JP: Prevalence of hemochromatosis among 11,065 presumably healthy blood donors. N Engl J Med 318: 1355-1362, 1988.

60. Powell LW, Subramaniam VN and Yapp TR: Haemochromatosis in the new millennium. J Hepatol 32: 48-62, 2000.

61. Hsing AW, McLaughlin JK, Olsen JH, Mellemkjar L, Wacholder S and Fraumeni JF Jr: Cancer risk following primary hemochromatosis: a population-based cohort study in Denmark. Int J Cancer 60: 160-162, 1995.

62. Fracanzani AL, Conte D, Fraquelli M, Taioli E, Mattioli M, Losco A and Fargion S: Increased cancer risk in a cohort of 230 patients with hereditary hemochromatosis in comparison to matched control patients with non-iron-related chronic liver disease. Hepatology 33: 647-651, 2001. 
63. Yang Q, McDonnell SM, Khoury MJ, Cono J and Parrish RG: Hemochromatosis-associated mortality in the United States from 1979 to 1992: an analysis of multiple-cause mortality data. Ann Intern Med 129: 946-953, 1998.

64. Elmberg M, Hultcrantz R, Ekbom A, Brandt L, Olsson S, Olsson R, Lindgren S, Lööf L, Stål P, Wallerstedt S, Almer S, Sandberg-Gertzén $\mathrm{H}$ and Askling J: Cancer risk in patients with hereditary hemochromatosis and in their first-degree relatives. Gastroenterology 125: 1733-1741, 2003.

65. Wang Y, Xie CL, Fu DL, Lu L, Lin Y, Dong QQ, Wang XT and Zheng GQ: Clinical efficacy and safety of Chinese herbal medicine for Wilson's disease: a systematic review of 9 randomized controlled trials. Complement Ther Med 20 143-154, 2012.

66. Michitaka K, Nishiguchi S, Aoyagi Y, Hiasa Y, Tokumoto Y and Onji M; Japan Etiology of Liver Cirrhosis Study Group: Etiology of liver cirrhosis in Japan: a nationwide survey. J Gastroenterol 45: 86-94, 2010.

67. Tanaka M and Wanless IR: Pathology of the liver in BuddChiari syndrome: portal vein thrombosis and the histogenesis of veno-centric cirrhosis, veno-portal cirrhosis, and large regenerative nodules. Hepatology 27: 488-496, 1998.

68. Okuda K: Inferior vena cava thrombosis at its hepatic portion (obliterative hepatocavopathy). Semin Liver Dis 22: 15-26, 2002.

69. Ren W, Qi X, Yang Z, Han G and Fan D: Prevalence and risk factors of hepatocellular carcinoma in Budd-Chiari syndrome: a systematic review. Eur J Gastroenterol Hepatol 25: 830-841, 2013

70. Raimondo G, Pollicino T, Cacciola I and Squadrito G: Occult hepatitis B virus infection. J Hepatol 46: 160-170, 2007.

71. Raimondo G, Allain JP, Brunetto MR, Buendia MA, Chen DS, Colombo M, Craxì A, Donato F, Ferrari C, Gaeta GB, Gerlich WH, Levrero M, Locarnini S, Michalak T, Mondelli MU, Pawlotsky JM, Pollicino T, Prati D, Puoti M, Samuel D, Shouval D, Smedile A, Squadrito G, Trépo C, Villa E, Will H, Zanetti AR and Zoulim F: Statements from the Taormina expert meeting on occult hepatitis B virus infection. J Hepatol 49: 652-657, 2008.

72. Nishikawa H, Arimoto A, Wakasa T, Kita R, Kimura T and Osaki Y: Lack of correlation between the antibody to hepatitis B core antigen and survival after surgical resection for hepatitis $C$ virus-related hepatocellular carcinoma. Oncol Rep 30: 91-98, 2013

73. Raimondo G, Caccamo G, Filomia R and Pollicino T: Occult HBV infection. Semin Immunopathol 35: 39-52, 2013.

74. Squadrito G, Pollicino T, Cacciola I, Caccamo G, Villari D La Masa T, Restuccia T, Cucinotta E, Scisca C, Magazzu D and Raimondo G: Occult hepatitis B virus infection is associated with the development of hepatocellular carcinoma in chronic hepatitis C patients. Cancer 106: 1326-1330, 2006.

75. Pollicino T, Squadrito G, Cerenzia G, Cacciola I, Raffa G Craxi A, Farinati F, Missale G, Smedile A, Tiribelli C, Villa E and Raimondo G: Hepatitis B virus maintains its pro-oncogenic properties in the case of occult HBV infection. Gastroenterology 126: 102-110, 2004

76. $\mathrm{Wu} \mathrm{HC}$ and Santella R: The role of aflatoxins in hepatocellular carcinoma. Hepat Mon 12: e7238, 2012.

77. Chen CJ, Wang LY, Lu SN, Wu MH, You SL, Zhang YJ, Wang LW and Santella RM: Elevated aflatoxin exposure and increased risk of hepatocellular carcinoma. Hepatology 24 38-42, 1996.

78. Kawaguchi T, Izumi N, Charlton MR and Sata M: Branchedchain amino acids as pharmacological nutrients in chronic liver disease. Hepatology 54: 1063-1070, 2011.

79. Price JA, Kovach SJ, Johnson T, Koniaris LG, Cahill PA, Sitzmann JV and McKillop IH: Insulin-like growth factor I is a comitogen for hepatocyte growth factor in a rat model of hepatocellular carcinoma. Hepatology 36: 1089-1097, 2002.

80. Buzzelli G, Dattolo P, Pinzani M, Brocchi A, Romano S and Gentilini P: Circulating growth hormone and insulin-like growth factor-I in nonalcoholic liver cirrhosis with or without superimposed hepatocarcinoma: evidence of an altered circadian rhythm. Am J Gastroenterol 88: 1744-1748, 1993

81. Kasprzak A and Adamek A: The insulin-like growth factor (IGF) signaling axis and hepatitis $\mathrm{C}$ virus-associated carcinogenesis (Review). Int J Oncol 41: 1919-1931, 2012.

82. Shimizu M,Kubota M, Tanaka T and Moriwaki H: Nutraceutical approach for preventing obesity-related colorectal and liver carcinogenesis. Int J Mol Sci 13: 579-595, 2012.
83. Hirosumi J, Tuncman G, Chang L, Görgün CZ, Uysal KT, Maeda K, Karin M and Hotamisligil GS: A central role for JNK in obesity and insulin resistance. Nature 420: 333-336, 2002.

84. Puri P, Mirshahi F, Cheung O, Natarajan R, Maher JW, Kellum JM and Sanyal AJ: Activation and dysregulation of the unfolded protein response in nonalcoholic fatty liver disease. Gastroenterology 134: 568-576, 2008

85. Duan XF, Tang P, Li Q and Yu ZT: Obesity, adipokines and hepatocellular carcinoma. Int J Cancer: Feb 12, 2013 (Epub ahead of print).

86. Asano T, Watanabe K, Kubota N, Gunji T, Omata M, Kadowaki T and Ohnishi S: Adiponectin knockout mice on high fat diet develop fibrosing steatohepatitis. J Gastroenterol Hepatol 24: 1669-1676, 2009.

87. Brakenhielm E, Veitonmäki N, Cao R, Kihara S, Matsuzawa Y, Zhivotovsky B, Funahashi T and Cao Y: Adiponectin-induced antiangiogenesis and antitumor activity involve caspase-mediated endothelial cell apoptosis. Proc Natl Acad Sci USA 101: 2476-2481, 2004

88. Kitade M, Yoshiji H, Kojima H, Ikenaka Y, Noguchi R, Kaji K, Yoshii J, Yanase K, Namisaki T and Asada K: Leptin-mediated neovascularization is a prerequisite for progression of nonalcoholic steatohepatitis in rats. Hepatology 44: 983-991, 2006.

89. Ikejima K, Takei Y, Honda H, Hirose M, Yoshikawa M, Zhang YJ, Lang T, Fukuda T, Yamashina S, Kitamura T and Sato N: Leptin receptor-mediated signaling regulates hepatic fibrogenesis and remodeling of extracellular matrix in the rat. Gastroenterology 122: 1399-1410, 2002.

90. Angulo P: Nonalcoholic fatty liver disease. N Engl J Med 346: 1221-1231, 2002.

91. Yang S, Zhu H, Li Y, Lin H, Gabrielson K, Trush MA and Diehl AM: Mitochondrial adaptations to obesity-related oxidant stress. Arch Biochem Biophys 378: 259-268, 2000.

92. Nowsheen S, Aziz K, Kryston TB, Ferguson NF and Georgakilas A: The interplay between inflammation and oxidative stress in carcinogenesis. Curr Mol Med 12: 672-680, 2012.

93. Marnett LJ: Oxyradicals and DNA damage. Carcinogenesis 21: $361-370,2000$

94. Petta $\mathrm{S}$ and Craxì A: Hepatocellular carcinoma and nonalcoholic fatty liver disease: from a clinical to a molecula association. Curr Pharm Des 16: 741-752, 2010.

95. Ishii H, Horie Y, Ohshima S, Anezaki Y, Kinoshita N, Dohmen T, Kataoka E, Sato W, Goto T and Sasaki J: Eicosapentaenoic acid ameliorates steatohepatitis and hepatocellular carcinoma in hepatocyte-specific Pten-deficient mice. J Hepatol 50: 562-571, 2009.

96. Ratziu V, Giral P, Charlotte F, Bruckert E, Thibault V, Theodorou I, Khalil L, Turpin G, Opolon P and Poynard T: Liver fibrosis in overweight patients. Gastroenterology 118: 1117-1123, 2000.

97. Adinolfi LE, Gambardella M, Andreana A, Tripodi MF, Utili R and Ruggiero G: Steatosis accelerates the progression of liver damage of chronic hepatitis $\mathrm{C}$ patients and correlates with specific HCV genotype and visceral obesity. Hepatology 33 1358-1364, 2001.

98. Westin J, Nordlinder H, Lagging M, Norkrans G and Wejstal R: Steatosis accelerates fibrosis development over time in hepatitis $\mathrm{C}$ virus genotype 3 infected patients. J Hepatol 37: 837-842, 2002.

99. Takuma Y and Nouso K: Nonalcoholic steatohepatitis-associated hepatocellular carcinoma: our case series and literature review. World J Gastroenterol 16: 1436-1441, 2010.

100. Duan XY, Qiao L and Fan JG: Clinical features of nonalcoholic fatty liver disease-associated hepatocellular carcinoma. Hepatobiliary Pancreat Dis Int 11: 18-27, 2012.

101. Reddy SK, Steel JL, Chen HW, DeMateo DJ, Cardinal J, Behari J, Humar A, Marsh JW, Geller DA and Tsung A: Outcomes of curative treatment for hepatocellular cancer in nonalcoholic steatohepatitis versus hepatitis $\mathrm{C}$ and alcoholic liver disease. Hepatology 55: 1809-1819, 2012.

102. Li T, Qin LX, Gong X, Zhou J, Sun HC, Qiu SJ, Ye QH, Wang L and Fan J: Hepatitis B virus surface antigen-negative and hepatitis $C$ virus antibody-negative hepatocellular carcinoma: clinical characteristics, outcome, and risk factors for early and late intrahepatic recurrence after resection. Cancer 119 126-135, 2013

103. Malik SM, Gupte PA, de Vera ME and Ahmad J: Liver transplantation in patients with nonalcoholic steatohepatitis-related hepatocellular carcinoma. Clin Gastroenterol Hepatol 7: 800-806, 2009 
104.Giannini EG, Marabotto E, Savarino V, Trevisani F, di Nolfo MA, Del Poggio P, Benvegnù L, Farinati F, Zoli M and Borzio F: Hepatocellular carcinoma in patients with cryptogenic cirrhosis. Clin Gastroenterol Hepatol 7: 580-585, 2009.

105. Tokushige K, Hashimoto E, Yatsuji S, Tobari M, Taniai M, Torii N and Shiratori K: Prospective study of hepatocellular carcinoma in nonalcoholic steatohepatitis in comparison with hepatocellular carcinoma caused by chronic hepatitis C. J Gastroenterol 45: 960-967, 2010.

106. Kusakabe A, Tanaka Y, Orito E, Sugauchi F, Kurbanov F, Sakamoto T, Shinkai N, Hirashima N, Hasegawa I, Ohno T, Ueda R and Mizokami M: A weak association between occult HBV infection and non-B non-C hepatocellular carcinoma in Japan. J Gastroenterol 42: 298-305, 2007.
107. Hatanaka K, Kudo M, Fukunaga T, Ueshima K, Chung H, Minami Y, Sakaguchi Y, Hagiwara S, Orino A and Osaki Y: Clinical characteristics of nonBnonC-HCC: comparison with HBV and HCV related HCC. Intervirology 50: 24-31, 2007.

108. Nishikawa H, Osaki Y, Takeda H, Sakamoto A, Saito S, Nishijima N, Nasu A, Arimoto A, Kita R and Kimura T: Effect of body mass index on survival after curative therapy for non-B non-C hepatocellular carcinoma. J Gastrointestin Liver Dis 22: 173-181, 2013

109. Cauchy F, Zalinski S, Dokmak S, Fuks D, Farges O, Castera L, Paradis V and Belghiti J: Surgical treatment of hepatocellular carcinoma associated with the metabolic syndrome. Br J Surg 100: 113-121, 2013. 